\title{
VR display of the stone statue of a general and the study of armor culture
} Yang, Cao *

Nanjing Normal University, kent_1019@163.com

Xinke, Huang

Nanjing Normal University, 10486394@@qq.com

Qinyou, zhou

Nanjing Normal University, 5201435@qq.com

\begin{abstract}
This paper takes the VR animation display of the Ming Xiao Mausoleum General stone statue life as an example to study the advantages of VR animation in the display of material heritage. Combined with literature and pictures, the digital restoration of the Ming Xiao Mausoleum stone statue is carried out in MAYA and Z brush, and the construction of the scene and the output of the final effect are realized in UE4.
\end{abstract}

Keywords: Relics protection, Protection of material heritage, VR animation, Stone statue, The Ming Xiao Mausoleum,

\section{INTRODUCTION}

The significance of studying the Ming-style armor modeling of warriors in Chinese animation is threefold. Firstly, in modern film and television animation design, costume modeling is an extremely important element in the characterization of film and television animation. Firstly, in modern animation design, costume design is a very important element in the characterization of film and television animation. Armor design is a kind of costume design, and it is also an indispensable element in shaping the image of generals in animation. Secondly, Ming-style armor modeling structure is the classic modeling structure of China's armor, and the modeling design of the armor of warriors in many animated films have borrowed the elements of Ming-style armor modeling. Finally, animation is a medium of cultural export, and the rationalization of martial armor in Chinese animation is also a way to promote our armor culture.

1.1 Reliable sources for studying the shape of Ming-style warrior armor

Most of the unearthed armors are only metal fragments, so the study of armor culture mainly comes from documentary materials, sculptures and paintings. Nowadays, most of the documentary materials about Ming style armor are preserved, but there are few physical armor materials, and the armor carved on the stone statues of Ming Dynasty generals is a reliable source for studying Ming style armor culture. Nanjing has preserved a lot of physical materials of Ming Dynasty statues, and these materials provide rich empirical references for the study of Ming-style armor.

1.2 Supplementation on the image material of generals in the creation of animation art

From the current data, the source of the creation of the image of warriors in animation works is mainly from opera, door god painting, etc., but there are less data to study the image of warriors from the perspective of the Ming Dynasty warrior stone statue life, this paper selects the Ming Dynasty warrior stone statue life as the research object, also as a supplement to the creation of the image of warriors in animation art.

1.3 Ethnic elements increase the vitality of animation characters

\footnotetext{
* Cao Yang is currently an associate professor at Nanjing Normal University, the director of the Animation Department of the School of Fine Arts of Nanjing Normal University, and a visiting scholar at the National Center for Computer Animation (NCCA) in the UK. His main research interests are computer animation and visual design.
} 
Whether from the facial features, the overall modeling characteristics, or the unique armor shape, the design elements with national characteristics can be extracted and applied to the character design of animation. Integrating ethnic elements in the design of animation characters is undoubtedly an important way to give animation characters uniqueness and add new vitality to them.

\section{CONTEXT OF THE RESEARCH}

\subsection{The situation of general stone statues in the Ming Dynasty}

Stone statues, also known as "Weng zhong", that is, carved from stone into the image of people and animals, stone statues are installed in front of the emperor's tomb stone people, stone beasts, is the epitome of imperial power. Placed on both sides of the sacred path in front of the tomb, to symbolize life, the shape of the image of life as the standard, also known as elephant life. The setting of the stone statue is also a symbol of the tomb owner's ritual guards, emphasizing the majesty of the deceased. This practice began in the Qin and Han dynasties, and has been used by emperors and important ministers since then, only the number and take the image varies.

From the founding of the Ming Dynasty by Emperor Zhu Yuanzhang to the Manchu Qing Dynasty, there were 16 reigning emperors during the 276 years of the Ming Dynasty. During the Hong wu period, Zhu Yuanzhang posthumously honored his parents and three generations of ancestors, and built the Ming Emperor's Mausoleum and the Ming Ancestor's Mausoleum in his hometown of Feng yang and Xu yi respectively; at the same time, he built the Ming Xiao Mausoleum for himself and Empress Ma in Nanjing's Zijinshan Mountain. The Ming Emperor Zhu Houchong from Hubei Zhong xiang into the capital after ascending to the throne, also posthumously his own parents as the empress, and changed the King Xing xian Mausoleum for the obvious tomb. Therefore, there were actually five surviving Shinto statues of imperial tombs during the Ming Dynasty.

According to the funeral system of the Ming Dynasty, in addition to the imperial tomb in front of the stone statue of the Shinto, the Shinto stone statue of the minister of the second rank or more will be set stone man, stone horse, stone sheep, stone tiger, stone watch pillar 2 pieces each. Among them, the image of the general stone statue is divided into less general and old general, in the Ming Dynasty, the tomb of Xu Da, stone carving larger, carving is also fine, become the existing testimony, the image of the general stone statue of the representative existence. With the change of the times, the existence of stone inscriptions on the tomb of a minister of merit and on the Shinto path has changed greatly. In Zhu Sew's "A Photographic Collection of Famous Places of Jinling Monuments", they still exist, but nowadays they no longer exist; other stone statues were preserved centrally. Some graves were excavated and the location of the graves was unknown; some were excavated and cleaned up and then backfilled and protected; and some were excavated and cleaned up and then protected and opened. The research objects of this thesis are mainly the stone statues of Ming Dynasty generals in Nanjing, and the stone statues of Ming Dynasty generals in other regions are mainly based on literature and pictures. Through the fieldwork, picture data and literature, the overall generalization of the Ming Dynasty martial stone statue life's modeling characteristics and armor characteristics. At the same time, the stone statues of warriors in the early Ming dynasty, represented by the Ming ancestral tomb, were modeled after the stone statues of Song dynasty tombs. Therefore, this paper will also study the modeling characteristics of some of the Song dynasty tombs, and through comparative analysis, gain a deeper understanding of the characteristics of the modeling and armor features of the Ming dynasty warrior statues.

\section{$\mathbf{2 . 2}$ research status of general stone statues in the Ming Dynasty}

There are two main sources of literature for domestic research on Ming Dynasty stone statue students: one is the records of ancient texts, such as the Ming Canon, the National Dynasty Canon, the Royal Ming Ceremony, and the Kingdom Ceremony, etc. These ancient texts record the regulations and types of Ming Dynasty stone statue students. But the age is long, and many materials do not match with the results of later scholars' examination, and there are information errors. Another is the literature research. As of March 2021, there are 398 pieces of literature 
searched from the knowledge network with the keywords of stone statue and Shinto stone carvings, among which there are about 70 pieces of research on Ming Dynasty stone statue. Among the literature that studied stone statues of Ming Dynasty, most of them studied the Accessibility regulations, types and existing conditions of stone statues of Ming Dynasty, about 6 articles studied the artistic style of stone statues of Ming Dynasty, 1 article studied the costumes of stone statues of Ming Dynasty generals, and 1 article studied the costumes of stone statues of civil officials in Ming imperial tombs.

Wu Dongsheng in his article "On the Artistic Style of the Stone Statue of the Gods of Ming Xiao Mausoleum" compares the stone statue of the general of Ming Xiao Mausoleum with those of different dynasties in history, studying the differences between the statue and those of other eras in terms of posture and dynamics, modeling techniques, and forms of expression, and summarizing the unique artistic style of the stone statue of Ming Xiao Mausoleum, which mentions that the overall modeling of the stone statue of the general presents a solemn artistic style and its highly Among them, it is mentioned that the overall shape of the stone statues of generals presents a solemn artistic style and their highly decorative armor. In Ding Boyu's "A Study of the Art of Stone Carving in the Divine Paths of Ming Dynasty Kings' Tombs: The Example of King Zhuangjian's Tomb in Jingjiang" and Qian Xiren's "On the Art of Stone Carving in the Tombs of Ming Ministers in Nanjing", it is mentioned that the basic art form of stone statues of ancient Chinese kings' tombs was finalized in the Ming Dynasty, absorbing the stylistic features of the Tang and Song dynasties, and that the Ming Dynasty stone statues were more lifelike and anthropomorphic in general. And anthropomorphic features. Zheng Yehong's article "A Study of the Costumes of Generals Carved in Stone at the Thirteen Ming Tombs" is an in-depth analysis of the armor of generals based on a combination of empirical evidence and argumentation, using the well preserved stone statues of generals at the Thirteen Ming Tombs as a carrier, and is of great value to the study of the culture of armor in the Ming Dynasty. In his book "Digital Survival", the American scholar Nicholas Negroponte said, "Computing is no longer only about computers; it determines our survival". Some of the world's leading museums are carrying out computer modeling of cultural heritage for conservation, exhibition and research, paying more and more attention to data collection, organization, classification, output and application of cultural heritage.

\section{RELATED WORK}

Although China's digital research in the field of cultural and museum conservation started in the 1990s, it was not until 2017 that the "12th Five-Year Plan" National Science and Technology Support Program led to the acceptance of the project "Research and Demonstration of Digital Conservation Standard System and Key Standards for Cultural Relics". In recent years, relying on computer and optoelectronic technology, the project has been implemented. In recent years, relying on the great development of computer and photoelectric technology, China has made great achievements in "museum digitization" and "virtual roaming of cultural heritage", such as the digital conservation projects of Dunhuang Mogao Caves, Longmen Grottoes, the National Palace Museum, the Three Gorges Cultural heritage digital exhibition project, etc. In his article "Digital Conservation and Design of Southern Dynasty Rock Carvings", Yang Xiangming mentions the use of 123D Catch photo modeling technology for 3D modeling and digital restoration of Southern Dynasty rock carvings. Ge Huaidong et al. mentioned the introduction of 3D reconstruction system and panoramic spatial measurement technology to embark on the digital conservation of stone carvings of Southern Dynasty tombs in their "Research on 3D digital conservation of stone carvings of Southern Dynasty tombs". Hou Secle mentioned three methods of digitizing stone carvings in the article "3D information retention and application of stone relics": traditional measurement, close-up photogrammetry method, and 3D laser scanning method.

Eva and Andrea of the CNR-IENI Institute in Italy developed a 3D virtual reconstruction of two important Etruscan tomb carvings from the Orientalization period in an Etruscan EU project in 2011-2013, focusing on communication needs, design, media mix, interactive interfaces and representation, and envisioning the 3D virtual 
reconstruction as a digital ecosystem that includes. 3D reconstruction, content creation, interactivity. Crs4 research center developed an interactive system using ancient Mediterranean sculptures as research objects to explore 3D models for high precision display in museums. Combining an object-aware interactive camera controller with an interactive user interface provides useful insights for the design of 3D probing user interfaces in future digital installations (Marco, Fabio et al., 2017). Analyzing 3D virtual reconstruction in a broad sense, different levels of visualization should be integrated: visualization combining real and virtual; 3D model metadata visualization; narrative visualization; behavioral visualization; and interactive tools visualization. To achieve "reconstruction" and artistic "processing" in a specific cultural context. Although 3D virtual reconstructions have made great progress in recent years in terms of digitization processes, computer mapping techniques, and archiving strategies, most virtual museums are still limited by communication methods, lacking visitor interaction, narrative metaphors, and emotional impact.

\section{Method Overview}

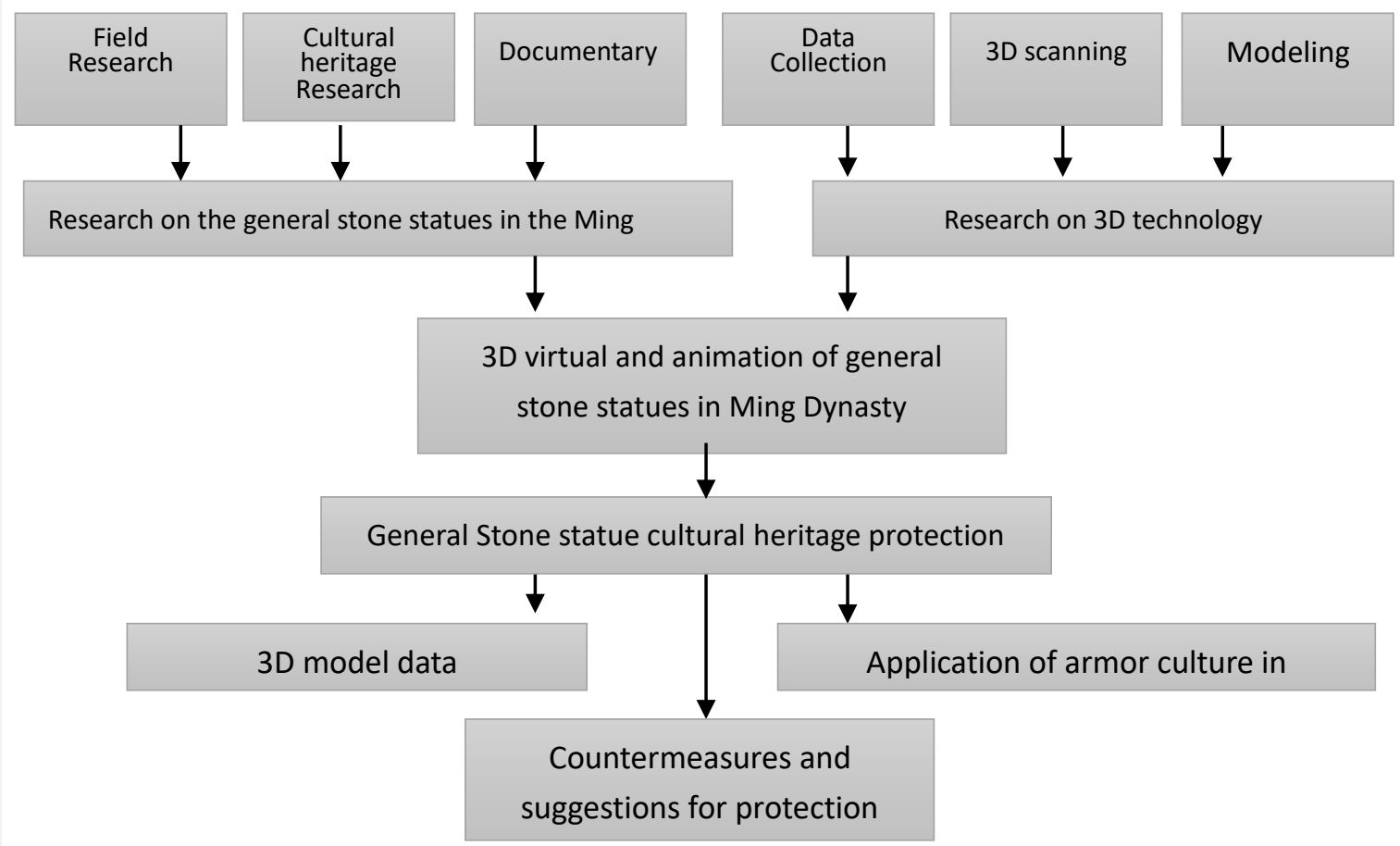

Fig.1 Method

The characteristics of Ming-style armor in the Ming Dynasty can be analyzed by combining the structural features of the armor on the stone statues of generals in Ming Xiao Mausoleum and Ming Thirteen Tombs. The structure of Ming-style armor from top to bottom is: the head wears a hood in the shape of a round mantle, and the top long tassel is draped behind. Inside wearing lining (including petticoat), petticoat outside wearing, hanging a full set of armor; its upper limb armor including shoulder, arm and other parts, shoulder guard beast head beast mouth fully open, shoulder guard armor clothing by beast mouth spit, long and elbow, elbow at the big sleeve cuffs turned backward or inverted lute shape, or robe sleeve hanging, or tied treasure beads in the end of the robe; small arm bundle with arm title, decorated with armor piece; torso armor protects the front chest and back, chest with heart mirror, uniform Fixed in the ring zale armor taping; followed by abdominal armor, waist armor and leg armor. Under the leg skirt, falcon tail, stirrup boots.

4.1 Research objects 
4.1.1 the field research object is mainly Jiangsu has been included in the national, provincial and municipal three levels of cultural relics protection units, as well as although not graded but after investigation and assessment of the tomb, site, stone carvings and so on that there is indeed a general stone statue of life.

4.1.2 Intangible cultural heritage: traditional opera, folk dance, folk music, folk literature, folk amusement, folk customs, historical place names, etc. related to the Ming dynasty stone statue Sheng armor of Jiangsu.

4.1.3 Documentary heritage: the relevant canonical texts, books, writings, inscriptions, paintings, etc. Related to the historical records of the stone statues of Jiangsu generals.

4.2 General Framework

4.2.1 Investigate and record the content of the legacy of the stone statue of a general living in the imperial tombs of the Ming Dynasty in Jiangsu.

4.2.2 Analysis of the historical origin of the stone statues of generals born in the imperial tombs of the Ming Dynasty in Jiangsu.

4.2.3 Analysis of the similarities, differences and mutual influences of the martial stone statues born in various cities in Jiangsu such as Nanjing and Huai'an City.

4.2.4 From the perspective of heritage theory, based on the cultural heritage resources of Jiangsu martial arts statue life, according to the type of cultural heritage (mainly including tangible, intangible and documentary) criteria for classification and value analysis, to explore the traditional culture of Jiangsu related to martial arts statue life; to form a more complete system of cultural heritage of Jiangsu martial arts statue life.

4.2.5 Through the investigation and research on the current situation of the protection and utilization of stone statue life heritage inside and outside the province, assess the level of protection and utilization of stone statue life cultural heritage in Jiangsu. Put forward research countermeasures and suggestions for future conservation work.

4.2.6 The representative stone statue of life for three-dimensional scanning and data collection, the establishment of three-dimensional model database, and extended to the field of animation film and television creation.

\section{VR modeling process}

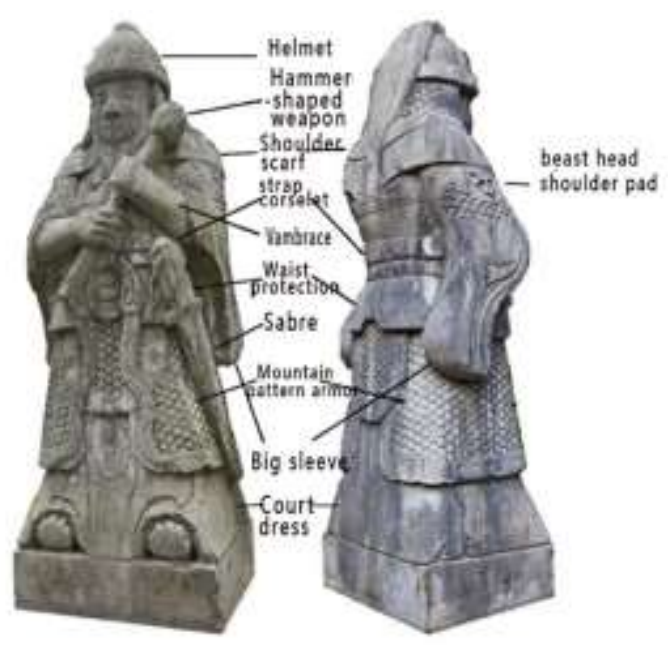

Fig. 2

\subsection{Preliminary Preparation}

The overall state of preservation of the Ming Xiao Mausoleum stone statues of generals is good, there are less generals and old generals, the length, width and height are $0.9 * 1.2 * 3.2(\mathrm{~m})$, but some details of the carving become blurred because of the weather, in order to understand the composition of each part of the generals in detail, combined with the data for the Ming Imperial Mausoleum stone statues of generals and the Ming Thirteenth 
Mausoleum stone statues of generals, and refer to the description of the armor in the "General Principles of Military Science". In order to understand the structure of each part of the warriors, we combined the records of the Ming Emperor's mausoleum and the Ming Thirteenth Mausoleum with the descriptions of the armor in the General Principles of Military Science.

5.2 Mid-production

After learning the detailed composition of the stone statue of a general living in Ming Xiao Mausoleum, the data model was constructed in MAYA and Z-brush. The main frame was sculpted in Z-brush, and after obtaining the
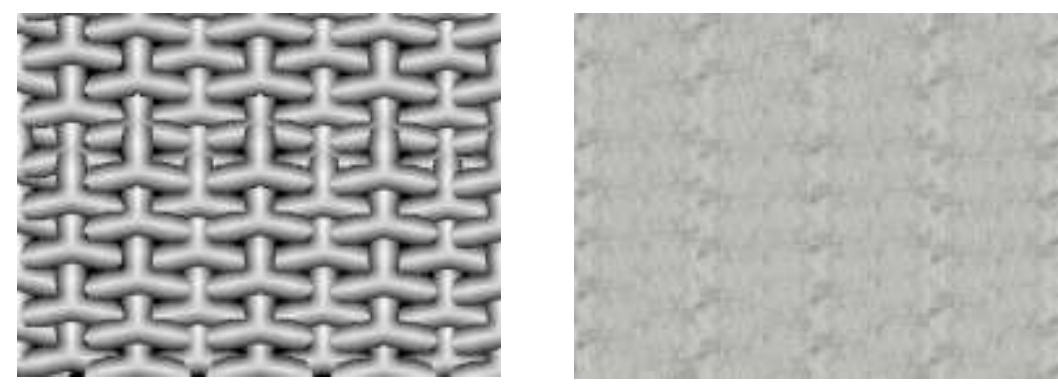

low

model, the decoration of the helmet, the sword and other right-angle edges were modeled in MAYA. The brushes used in Z-brush are Clay Buildup, Standard, Dam Standard, Move, and Trim Adaptive, and their brush Z strength and RGB strength are around 25. Because the armor of the stone statues are all the same mountain pattern armor, a similar texture of the mountain pattern armor was created with PS (Figure 4-2), and a new texture brush was created in combination with the alpha function in Z-brush to complete the armor texture sculpting. After completing the carving of the stone statue, use Z-brush's surface reduction master to reduce the surface of the model to obtain a low model with few surfaces, and then export the model to MAYA for adjustment. Unfold the uv of the model, and according to the material of the dolomite of the stone statue (Figure 4-3), finish making the basic material in PS. At this point, the digital model of the Ming Xiao Mausoleum general was completed (Figure 4-4). After creating the data model, you have to refine the environment in which the model is located. Import the model into Unreal Engine

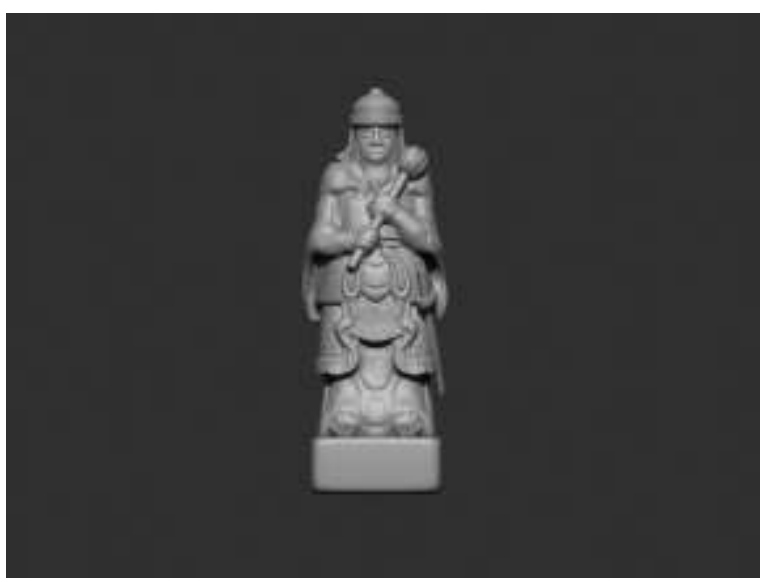

4 here and create a new project. Edit the environment with the help of the terrain tool in Unreal Engine 4. Referring to the current overall arrangement and layout of the martial arts stone statues born in Nanjing's Mingxiao Mausoleum, the necessary plants were brushed out with the vegetation tool, and then the details were adjusted. In addition, the overall scene Light set three: Atmospheric Fog, Directional Light and Sky Light, to meet the lighting effect of the 
scene, and finally to enhance the scene effect added some steam particle effects to complete the environment layout (Figure 4-5).

\subsection{Post-rendering output}

After completing the overall construction of the model and scene in the mid-term, we then have to realize the shot editing of VR animation. The animation needs to arrange certain storyline and event triggers to guide the viewer's viewing of the material heritage, so as to achieve the interactivity and immersion unique to VR animated digital heritage displays. To achieve these two purposes, the Add Level Sequence animation tool in Unreal Engine 4 was used to create the footage.

A total of two shots were designed for the animated display of the martial arts statue life, which are the general advancement of the overall scene and the display of the individual statue life. After adjusting the shots, render out the film. (Figure 4-6)

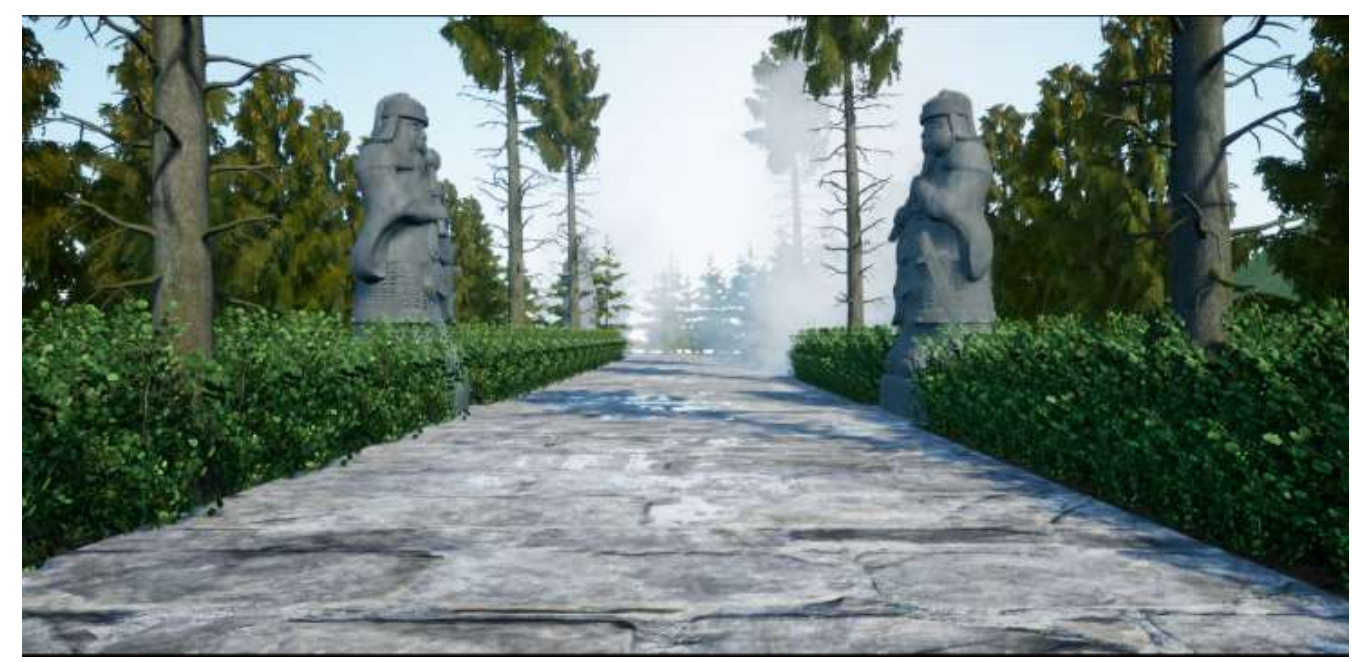

\subsection{Analysis}

In order to understand the experience of the viewers on the VR animation display of the Ming Xiao Mausoleum martial arts statue, I designed a questionnaire and randomly sampled 100 people with the help of Questionnaire Star. Among the 100 randomly sampled people the youngest people aged 15 to 25, with a general monthly income of 2,000 to 4,000 yuan. Seventy percent of them had never been to Nanjing Mingxiao Mausoleum Park, and 63\% of them were not sure about the history of the stone statues born in Nanjing Mingxiao Mausoleum. However, in the results of this VR animation display of the Ming Xiao Mausoleum martial arts statue life, the satisfaction of the viewers' experience reached $75 \%$. The main reasons for the dissatisfaction of the viewers are that the restoration effect of the stone statue of the general is not good, the scene effect is not good, the environment sound is not comfortable and the lack of historical information explanation, etc. At the same time, $92.16 \%$ of people said that they are willing to experience the scenic spots of different places at home if they have the conditions (see the chart below). Through the above data, we can find that most young people are still willing to try VR animation display projects of material heritage. Of course, when watching VR animation, some viewers also said that the realism of VR animation scene restoration is not enough, if the realism of the scene can be increased, then the viewer's immersion will also be greatly increased. 

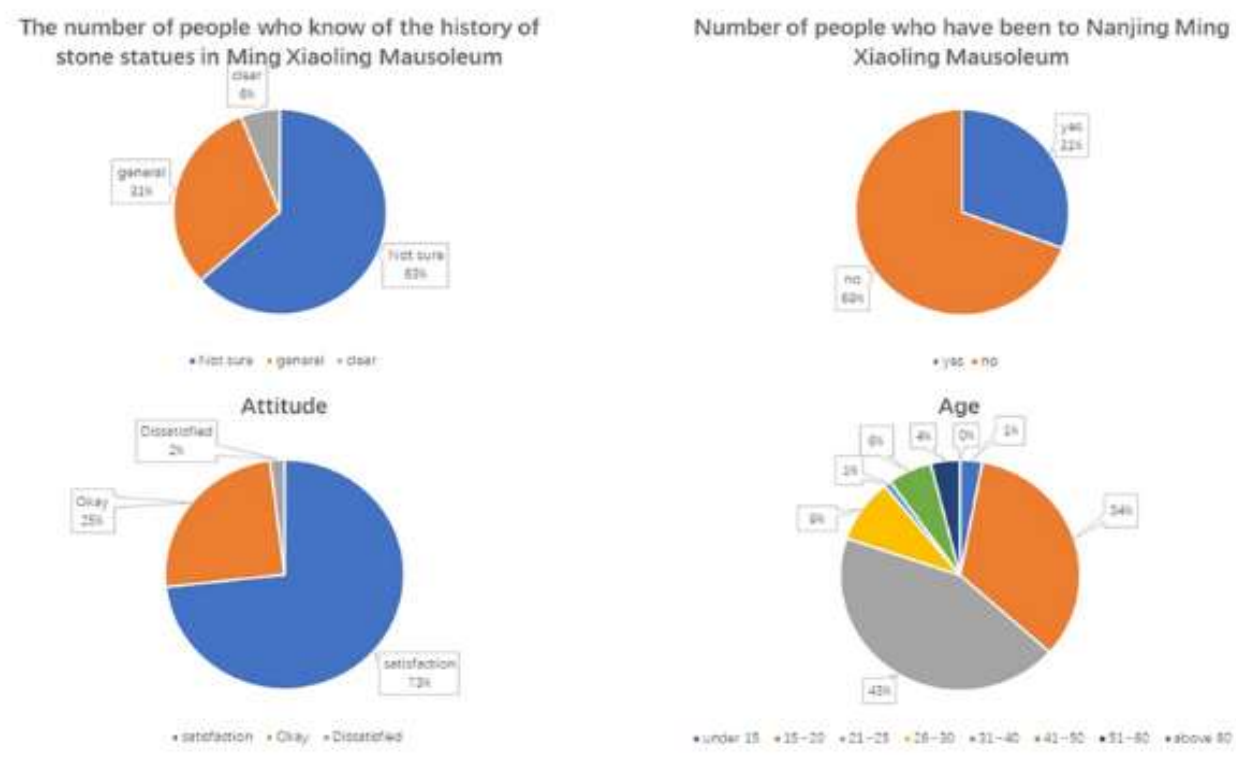

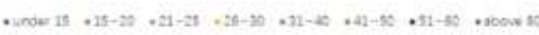

VR animation can show the material heritage in multiple directions, with appropriate camera movement and voice text introduction, which can greatly increase the viewer's immersion in viewing the material heritage. Digital heritage is mainly constructed by 3D modeling and digital scanning, which can restore the heritage and also repair the broken and damaged parts of the heritage. At the same time, I am also thinking, in the restoration of digital heritage, for the restoration of digital heritage, should be made old or restore to the original new look of the heritage. Compared with the traditional display of cultural relics, its material heritage display is a static, and VR animation it is not a static display of cultural relics, we can show the cultural relics from the new look to the old look, this dynamic process, to tell the historical reasons for the breakage of material cultural relics, weather reasons or human reasons. This broadens the advantageous nature of digital artifacts in the way artifacts are displayed. The significance of digital artifacts is not only to preserve the artifacts, but more importantly, to give full play to its edifying function so that future generations can see these crystals of human wisdom.

The traditional way of displaying cultural heritage is based on "authenticity", and in order to let the viewers understand the material heritage more deeply and directly, the traditional way of displaying it is mainly through museum displays and the establishment of theme parks, such as the Terracotta Warriors and Horses Museum and Ming Xiao Mausoleum Park. The advantage of this kind of material heritage display method is to protect the material heritage from being destroyed at the same time, the viewer can contact the cultural relics face to face, but because of the geographical location or traffic, the number of audience is limited, the display of cultural relics cannot be widely spread. 3D animation has broken this limitation of time and space, the viewer can experience the dynamic display of cultural relics anytime and anywhere, at the same time, 3D animation also has the function of historical and cultural education. The biggest feature of 3D technology is the viewer's unique immersion and interactivity, while the biggest feature of animation is the expression of the story, which is used in the display of tangible heritage, not only to meet the viewer's off-site experience, but also to increase the viewer's immersion and interactivity in the experience. At the same time, it is also an innovative mode to strengthen the national memory and spread the culture of Chinese characteristics by applying the achievements of tangible heritage to the creation of animation in the "original" way. The lack of research on 
armor culture in film and game animation has also made many people realize the importance of related research. Many armor enthusiasts are showing the armor culture of China through restoration of armor, armor exhibition and new media communication. For example, Jiang Feng, an armor restorer, spent two years to restore the Great Tang Ming Guang armor and successfully restored the first set of Shan wen armor in China; Li Hui, an armor restorer, held a personal exhibition of Xuanjin armor culture in Beijing in 2020, exhibiting various kinds of armors of different dynasties in China's history; according to statistics, the plays of videos about armor on video platforms such as Jitterbug and B station reached millions of times. As a unique culture in the long history, armor is becoming more and more popular among the public, and the complex and fine design details meet the visual aesthetic needs of contemporary people.

\section{CONCLUSION}

Chinese armor has gone through the genesis of the Qin Dynasty, the initial formation of the Qin and Han Dynasties, the innovation of the North and South Dynasties, the great success of the Sui and Tang Dynasties, and the peak of the Song Dynasty, and by the Ming Dynasty it was already a mature and definitive period for the development of Chinese armor. The steady continuation for hundreds of years finally presented a mature set of armor with strong national characteristics to the world. The study of armor is not only the study of the modeling characteristics of armor, but also the study of the cultural and spiritual connotation of armor through the culture of armor. The study of armor is not only to study the characteristics of armor, but also to study the culture and spirit of armor through the culture of armor. This paper takes the Ming-style armor of a warrior in animation art as the starting point, compares and analyzes the characteristics of the traditional Ming-style armor of a warrior in the stone statue of a Ming Dynasty warrior, and draws the similarity between the armor of a warrior in animation works and the armor of a traditional culture, and also compares and analyzes the characteristics of the armor design of a warrior in foreign animation works, so as to gain inspiration for the armor design of a warrior in animation works. Works of art play a role in the overall cultural construction, which may contain the religious beliefs, moral standards, and aesthetic views of that culture, as well as reveal the different hierarchies, boundaries, and taboos of social classes, and the function of maintaining and immortalizing them. The application of traditional culture to the creation of animation allows the creator to create an animated image while having a cultural heritage in it. Chinese animation, the early focus on the combination with traditional art, very nationalized, localized characteristics, enjoy the "Chinese school" of the world reputation. The general principle of art is the same, but the art of each nationality, to have the style of each nationality, this different style is its national achievement. This shows that each national art has its own achievement because of its national characteristics. Therefore, Chinese animation can only create classic works if it is rooted in traditional art, follows the spirit of the Chinese nation and conforms to the aesthetic habits of the nation.

Aesthetic style is the unification of the content and form of a work, and the formation of aesthetic style has its own subjective and objective reasons. This section discusses the difference between the aesthetic style of Ming-style armor modeling in animation and the aesthetic style of Ming-style armor modeling in stone statue life mainly based on the difference in the background of the times, which in turn shows the difference in the artistic expression of Ming-style armor. In the context of the Ming dynasty era, the Ming-style armor design of Ming Dynasty general stone statue presents the imitation of the previous dynasty in the early Ming Dynasty, the civil dressing of the military in the middle of Ming and the elaborate decoration in the later Ming Dynasty, and the structure and shape of Mingstyle armor as a whole proceeds toward complex decoration. Comparing and analyzing the silhouette shape of the Ming warrior stone statues from different regions, it can be seen that the Ming warrior stone statues as a whole look like a blunt square triangle with a very distinctive head helmet and an overall line trending downward to tighten. From the analysis of the height ratio and costume features of the warrior general, the height of the warrior general is 
about 2.7-2.9 meters, the height-to-head ratio is about 5:1 more, as well as 6:1, etc. The ratio of head width to body width is about $1: 2$, the width is about $0.9-1.1$ meters, and the thickness is about 0.6-0.9 meters. The head and neck of the warrior general are connected and fused into one, which is extraordinarily thick, which also makes the overall appearance of the stone statue of the warrior general round and blunt. (See Figure 28.) The line of the neck and shoulders of the Ming dynasty statue is relaxed downward, the lines of the hands are either crossed or nearly intersected in front and behind, and the feet are either standing vertically in front of the eyes or standing in an outward figure. The structural composition of the Ming-style armor can be seen visually in Figure 29. From top to bottom, it is basically a helmet, uniform, leg skirt and boots, with ornaments on the side of the body. The difference of the neck is not so obvious, and the overall feeling presents a kind of tiger back and bear waist. Gong Cheng bo in "The History of Chinese Animation" Gong Cheng bo in "The History of Chinese Animation" divides the history of Chinese animation into six stages, namely, the beginning (1923-1946), the development and boom (1947-1965), the downturn and interruption (1966-1976), the Recovery and reconstruction (1977-1994), transformation and pain (1984-1994) and opportunity and challenge (1995-2013). The animation character shapes in the background of different stages all represent, the aesthetic habits of people in the social background at that time. In this section, four animation works are selected to study the Ming-style armor of generals in animation, namely "The Proud General" in 1956, "The Little Gourd King" in 1990, "Zheng He Goes to the West" in 2008 and "Qi Jiguang" in 2014. "The Proud General", which was directed by Te Wei and Li Kewei and filmed by Shanghai Film Studio in 1956, was designed with reference to many national elements at the beginning of its image. Structure. The crocodile leader in the period of recovery and reconstruction of the animation work "gourd little vajra", using the form of papercutting art expression Ming-style armor, the structure of the traditional Ming-style armor, but the armor as a whole appears to be sharper. Late 80s, the United States, Japan animation film with its strong offensive, mature production mode and sophisticated market operation to seize the animation market in China. In the design of the image of warriors, it is more inclined to the beauty type, at this time the design of Ming-style armor focuses more on the slender beauty of the warriors.

[1] Fu Qingfang Development of virtual real scene display system of history and culture of Han zhaolie Temple based on UE4 engine [D] Xihua University, 2017

[2] Wu Dongsheng On the artistic style of Shinto stone statues in Xiaoling of Ming Dynasty [D] Nanjing University. 2012

[3] Gu Lipeng Application and function of three-dimensional digital technology in cultural relics protection [J] Identification and appreciation of cultural relics, 2020 (02): 74-76

[4] Zheng Xu Description of VR animation design based on game engine [D] Shaanxi Normal University, 2017 [5] Hui Tang,Guohua Geng,Mingquan zhou. Application of Digital Processing in Relic Image Restoration Design[J]. Sensing and Imaging: Continuing Subsurface Sensing Technologies and Applications,2019,21(9).

[6] Hu, QW (Hu, Qingwu),Yu, DB (Yu, Dengbo),Wang, SH (Wang, Shaohua), Fu, CW (Fu, Caiwu),Ai, MY (Ai, Mingyao) ; Wang, WD (Wang, Wende).INFORMATION VISUALIZATION.[J] Hybrid three-dimensional representation based on panoramic images and three-dimensional models for a virtual museum: Data collection, model, and visualization,2017,16(126-138)

[7] Spector, A. Z. 1989. Achieving application requirements. In Distributed Systems, S. Mullender, Ed. ACM Press Frontier Series. ACM, New York, NY, 19-33. DOI= http://doi.acm.org/10.1145/90417.90738. 